\title{
Reproducibility and validity of the food frequency questionnaire for estimating habitual dietary intake in children and adolescents
}

\author{
Tomomi Kobayashi ${ }^{1,2^{*}}$, Miharu Kamimura ${ }^{1,3}$, Shino Imai ${ }^{1}$, Chihiro Toji ${ }^{1,2}$, Naoko Okamoto ${ }^{4,5}$, Mitsuru Fukui ${ }^{6}$ and \\ Chigusa Date ${ }^{4,7}$
}

\begin{abstract}
Background: A previous study reported the development a 75-item food frequency questionnaire for Japanese children (CFFQ). The first aim was to examine the reproducibility and validity of the CFFQ in order to assess dietary intake among two groups; 3-11 year old children (YC group) and 12-16 year old children (AD group). The second aim was to use the CFFQ and the FFQ for adults (AFFQ), and to determine which was better suited for assessing the intake of children in each group.
\end{abstract}

Methods: A total of the 103 children participated in this study. The interval between the first CFFQ and AFFQ and the second CFFQ and AFFQ was one month. Four weighted dietary records (WDRs) were conducted once a week. Pearson's correlation coefficients between the first and second FFQs were calculated to test the reproducibility of each FFQ. Pearson's correlation coefficients between WDRs and the second FFQ were calculated for the unadjusted value and sex-, age-, and energy-adjusted values to determine the validity of each FFQ.

Results: The final number of subjects participating in the analysis was 89. The median correlation coefficients between the first and second CFFQs and AFFQs were 0.76 and 0.73 , respectively. There was some over/ underestimation of nutrients in the CFFQ of the YC group and in the AFFQ of the AD group. The medians of the sex-, age-, and energy-adjusted correlation coefficients were not different between the YC and AD groups for each FFQ. The correlation coefficient in sex-, age-, and energy-adjusted value revealed that the largest number of subject with high (0.50 or more) value was obtained by the CFFQ in the YC group.

Conclusions: This study indicated that the CFFQ might be a useful tool for assessing habitual dietary intake of children in the YC group. Although the CFFQ agreed moderately with habitual intake, it was found to underestimate intake in theAD group. However, for the AFFQ, the ability to rank habitual intake was low. Therefore, it is necessary to develop a new FFQ or modify an existing FFQ to accurately assess the habitual diet of children in the AD group.

\section{Background}

It is thought that childhood is not only the major period of growth, but is also the time when eating habits are formed [1]. An inactive lifestyle and long-term eating habits such as irregularity and overeating affect the initiation and onset of lifestyle-related diseases, such as obesity, diabetes, and cardiovascular disease. In order to

\footnotetext{
* Correspondence: yataka@giga.ocn.ne.jp

'Department of Food and Nutritional Sciences, School of Natural Science and Ecological Awareness, Graduate School of Humanities and Sciences, Nara Women's University, Kitauoya-nishimachi, Nara, 630-8506, Japan Full list of author information is available at the end of the article
}

prevent these diseases, it is desirable that individuals should acquire appropriate dietary habits during childhood. We cannot conduct weighed dietary records (WDRs) for extended periods of time for children because keeping a WDR puts a heavy burden on the participant's parents as surrogates. It is also not feasible to conduct 24-hour recall for multiple days in order to assess children's habitual dietary intake, because it is difficult to obtain accurate dietary information because children lack knowledge about foods and cooking methods [2-4]. Although the quantitative assessment of food

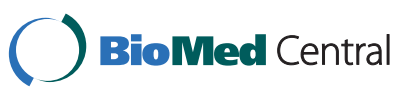


intake using a food frequency questionnaire (FFQ) may be less accurate compared with a WDR and 24-hour recall, it is a method that can assess the habitual dietary patterns of many subjects, even from a one-time investigation.

In many epidemiological studies, a FFQ originally developed for adults was applied for the assessment of dietary intake in children [5-8]. We thought that a dietary survey method for children was more suitable to assess their dietary intake than the method developed for adults. However, there have been no reports of the validity of the conventional FFQ for adults or of the FFQ for children in the Japanese pediatric population [9]. To prove our hypothesis, we previously developed a 75-item FFQ (CFFQ) to assess the habitual diets of Japanese children [10]. This CFFQ included the average portion size consumed by 3 to 11 -year-old children, including both the individual foods and the items in mixed dishes. However, the reproducibility and validity of this questionnaire in the target group needed to be examined. In addition, we wanted to confirm the validity of the FFQ in adolescents, because there have been no FFQs developed for adolescents in Japan [9].

The aims of this study were two-fold. The first aim was to examine the reproducibility and validity of the CFFQ in order to assess dietary intakes among two groups of children divided by age:, 3 to 11 year old children (YC group) and 12 to 16 year old children (AD group). The second aim was to determine more suitable FFQ for assessing the children's intake in both groups. To accomplish this, we applied the CFFQ and the FFQ for adults (AFFQ), which was previously developed for dietary assessment in adults by Date et al. [11], for the two groups of children.

\section{Methods}

\section{Subjects}

The study participants were healthy children enrolled at the kindergarten, elementary school, and secondary school attached to Nara Women's University. A total of 111 participants were chosen by the teachers of each school. We grouped the participants into a "Young Children" group (YC group; 3-11 years) and an "Adolescent" group (AD group; 12-16 years). We explained the purpose of the investigation and the methods to the parents/guardians of the YC group in May and June 2008, and to the participants in the AD group in October of the same year. A total of 103 parents/guardians (YC group $n=50$, $A D$ group $n=53$ ) gave written informed consent for their children to participate in this study. The study was approved by the research ethics committee of the faculty of human life and environment, Nara Women's University.

\section{Study design}

Figure 1 shows the design of the study. The two types of FFQs (the CFFQ and AFFQ) were conducted at the same time in random order for each subject. The first FFQs were conducted just before performing the first WDR. Then, the four-day WDRs were collected once a week, and on each different day of the week (3 weekdays and 1 weekend day). We initially allocated the days of the dietary survey for each subject at random. The second FFQs were conducted after the fourth WDR. The interval between the first FFQs and the second FFQs was one month.

\section{Food frequency questionnaires}

The FFQs were completed by the subjects' mothers in the $\mathrm{YC}$ group. In the $\mathrm{AD}$ group, the subjects self-administered the FFQs. We used two FFQs in this study. The two FFQs included questions about both individual food items and mixed dishes based upon the typical eating habits of normal Japanese children or adults.

The first was the CFFQ which was developed specifically for Japanese children. Details of the CFFQ were reported previously [10]. In brief, the CFFQ is a newly developed questionnaire for assessing the habitual

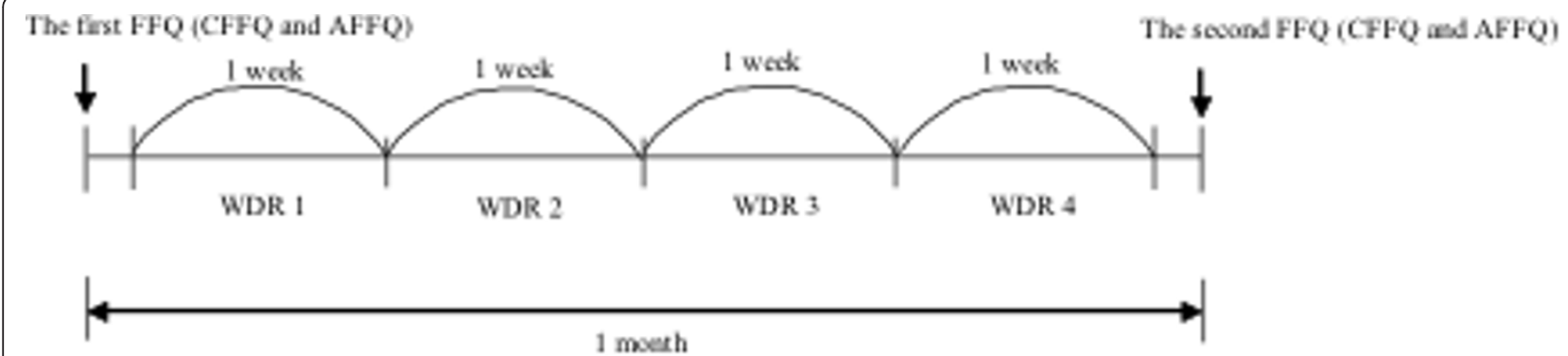

Figure 1 Design of the food frequency questionnaire reproducibility and validity study. The order of the CFFQ and AFFQ was random for each subject. We applied the FFQs and 4-day WDRs to 50 subjects in the YC group and 53 in the AD group. There were 89 subjects who completed all FFQs and the 4-day WDRs (YC group $n=48, A D$ group $n=41$ ). CFFQ: Food frequency questionnaire for dietary assessment in children. AFFQ: Food frequency questionnaire for dietary assessment in adults. WDR: Weighed dietary record. 
dietary intake of children during the previous month. The question items and portion size of the CFFQ were developed from the dietary data of 586 children (age: 3 to 11-years-old). The number of food items on the CFFQ is 75 .

The second was the AFFQ, which was developed for estimating the habitual dietary intake of Japanese adults [11]. The AFFQ is composed the 76-food items. The portion size of the AFFQ is tailored to the average of the dietary intakes of adults. We did not change the portion size in this study. Two items concerning alcohol intake were excluded, leaving 74 items on the AFFQ. The AFFQ was developed to report the adults' recall of their diets over the past year. In this study, the frequency response formats were modified to encompass the past month for each child's diet. In Japan, children are provided with lunch in elementary school on weekdays. Therefore, questions about school lunch were added in the AFFQ.

For both the CFFQ and AFFQ, the intake frequencies of the each question item on the FFQs were classified into four types: seven (i.e., everyday, 5-6 times per week, 3-4 times per week, 1-2 times per week, 2-3 times per month, 1 time per month, or never), eight (" $2-3$ times per day" was added to seven categories), nine ("4-5 times per day" was added to eight categories) and eleven ("8-10 times per day", "6-7 times per day" were added to nine categories) according to the general intake frequency of each item. We used photographs of each listed food item to estimate one portion. The estimation of portion size was classified into six categories referring to the photographs in full-scale size; that is, one-third, one-half, the same amount, 1.5 times, twice, and 'other'.

\section{Weighed dietary records}

We decided that the subjects' mothers would keep the WDRs for the YC group, and either the subjects or their mothers would keep them in the AD group. In order to measure the weight of foods, a digital cooking scale (TANITA digital cooking scale; KD-402-WH, Tokyo, Japan) was loaned to the subjects for the duration of the study. On a specified day, the weight of all foods and beverages that the subjects consumed, from getting up until going to bed, was measured. The dish name, food name and weight were recorded for each meal (breakfast, lunch, dinner and snacks). We asked the respondents to measure the weight of foods before cooking, as much as they could. The mean value of the four WDRs was defined as the subject's habitual intake for one month.

\section{Calculation of nutrient intake}

After the data from the first and second FFQs and the 4-day WDRs were collected, registered dieticians confirmed the content of the written survey forms. Any unclear points were inquired of the respondents, and then FFQs and WDRs were completed. We then calculated the nutrient intake for each child using the Standard Tables of Food Composition in Japan (fifth revised and enlarged edition) [12]. We calculated energy intake and intake of 26 nutrients (protein, total fat, carbohydrate, sodium, potassium, calcium, magnesium, phosphorous, iron, zinc, copper, manganese, retinol equivalent, vitamin $\mathrm{D}$, alpha tocopherol, vitamin $\mathrm{K}$, vitamins B1, vitamins B2, niacin, vitamin B6, vitamin B12, folic acid, pantothenic acid, vitamins $C$, cholesterol, dietary fiber), and 12 fatty acids (saturated fatty acid, monounsaturated fatty acid, polyunsaturated fatty acid, n-3 polyunsaturated fatty acid, n-6 polyunsaturated fatty acid, myristic acid, oleic acid, linoleic acid, alpha - linolenic acid, arachidonic acid, icosapentaenoic acid, docosahexaenoic acid) from the WDRs and FFQs.

\section{Statistical analysis}

The sample size was calculated to be appropriate for each group ( $\mathrm{p}<0.05,80 \%$ power). We considered that the mean value of nutrients from the four WDRs was the gold standard (follow WDRs). In order to test the reproducibility of the FFQs, the Pearson's correlation coefficient between the first and second FFQs was calculated. To test the validity of the FFQs, we calculated the percent difference of intake between the WDRs and the second FFQ, using the following formula: (the second FFQ - WDRs)/WDRs. The paired t-test was used to examine the difference in nutrient intake between the WDRs and the second FFQ. Pearson's correlation coefficients between the WDRs and the second FFQ were calculated for the unadjusted (crude value) and sex-, age-, and energy-adjusted values (adjusted value). Energy was adjusted by the residual method [13]. A Bland Altman analysis was used to assess the agreement of the measurements between the CFFQ and WDR or the AFFQ and WDR [14]. The differences between the two methods were plotted against the mean of the two methods. Desirable agreement between two methods would result in a difference of 0 .

We found that some nutrients were not normally distributed, so we calculated the natural log of these variables, attempting to correct for their non-normally. The statistical package SPSS for Windows 17.0 (SPSS Inc. Tokyo, Japan) was used for all statistical analyses.

\section{Results \\ Subjects}

Out of the 103 study participants, we excluded two individuals who did not eat their daily diet on the survey days; three who only kept WDRs for less than 2 days; and six who could not complete four FFQs (i.e, both the 
first and the second CFFQ and the AFFQ). Furthermore, using the cut-off value proposed by Willett [8], we excluded three subjects whose energy intake from the second CFFQ or AFFQ was $<800 \mathrm{kcal}$ or $>4000 \mathrm{kcal}$ for boys, and $<500 \mathrm{kcal}$ or $>3500 \mathrm{kcal}$ for girls. Therefore, the final number of subjects included for analysis was 89 (YC group $\mathrm{n}=48, \mathrm{AD}$ group $\mathrm{n}=41$ ). There were 15 children in kindergarten (3-5 years old), 18 in the lower grades of elementary school (6-8 years old), 15 in the upper grades of elementary school (9-11 years old), 24 junior high students (12-14 years old), and 17 high school students (15-16 years old).

\section{Reproducibility of the CFFQ and AFFQ}

Table 1 shows the Pearson's correlation coefficients for total energy, nutrients and fatty acids between the first and second CFFQs, and the first and second AFFQs for all of the subjects. The correlation coefficients varied from 0.67 for carbohydrate to 0.84 for pantothenic acid in the CFFQ, and from 0.39 for manganese to 0.83 for carbohydrate in the AFFQ. The median correlation coefficient was 0.76 in the CFFQ and 0.73 in the AFFQ. For both the CFFQ and AFFQ, there were significant positive associations for the energy and 26 nutrients and 12 fatty acids between the first and second FFQs.

\section{Validity of the second CFFQ}

Table 2 shows the intakes of total energy, nutrients and fatty acids determined from the WDRs, and from the second CFFQ in the YC and AD groups. The mean energy intake was not significantly different between the WDRs $(1,547 \pm 330 \mathrm{kcal} /$ day; i.e. mean $\pm \mathrm{SD})$ and the second CFFQ $(1,533 \pm 438 \mathrm{kcal} /$ day $)$ in the $\mathrm{YC}$ group. However the energy intake was found to be underestimated for the second CFFQ $(1,781 \pm 588 \mathrm{kcal} /$ day $)$ compared to the WDRs $(2,078 \pm 478 \mathrm{kcal} /$ day $)$ in the AD group. The median percent difference between the WDRs and CFFQ of nutrients were $-2 \%$ in the YC group and $-18 \%$ in the AD group, respectively. Table 3 shows the correlation coefficients of energy, nutrients and fatty acids between WDRs and the second CFFQ in the YC and AD groups. From the CFFQ, the median of the crude values for nutrients was 0.55 in the $\mathrm{YC}$ group and 0.28 in the AD group. The adjusted values varied from 0.03 for vitamin $C$ to 0.69 for magnesium in the YC group (the median; $r=0.39$ ), and from 0.15 for monounsaturated fatty acid and oleic acid to 0.77 for vitamin $C$ in the $A D$ group (the median; $r=0.34$ ).

\section{Validity of the second AFFQ}

There was the overestimate of the energy intake determined by the AFFQ in the YC group $(1757 \pm 538 \mathrm{kcal} /$ day) (Table 2). However, there was no significant change in the energy intake calculated from the AFFQ in the
Table 1 Pearson's correlation coefficient between the first and second FFQs for all subjects

\begin{tabular}{|c|c|c|}
\hline Nutrients & CFFQ & AFFQ \\
\hline & $\mathrm{n}=89$ & \\
\hline Energy (kcal/day) & $0.73^{* *}$ & $0.80^{* *}$ \\
\hline Protein (g/day) & $0.77^{* *}$ & $0.73^{* *}$ \\
\hline Total fat (g/day) & $0.76^{* *}$ & $0.71^{* *}$ \\
\hline Carbohydrate (g/day) & $0.67^{* *}$ & $0.83^{* *}$ \\
\hline Sodium (mg/day) & $0.76^{* *}$ & $0.75^{* *}$ \\
\hline Potassium (mg/day) & $0.77^{* *}$ & $0.72^{* *}$ \\
\hline Calcium (mg/day) & $0.78^{* *}$ & $0.78^{* *}$ \\
\hline Magnesium (mg/day) & $0.77^{* *}$ & $0.79^{* *}$ \\
\hline Phosphorous (mg/day) & $0.79^{* *}$ & $0.77^{* *}$ \\
\hline Iron (mg/day) & $0.74^{* *}$ & $0.67^{* *}$ \\
\hline Zinc (mg/day) & $0.79^{* *}$ & $0.76^{* *}$ \\
\hline Copper (mg/day) & $0.69^{* *}$ & $0.75^{* *}$ \\
\hline Manganese (mg/day) & $0.72^{* *}$ & $0.39^{* *}$ \\
\hline Vitamin A ( $\mu \mathrm{gRE} /$ day) & $0.72^{* *}$ & $0.72^{* *}$ \\
\hline Vitamin D (mcg/day) & $0.74^{* *}$ & $0.65^{* *}$ \\
\hline Alpha tocopherol (mg/day) $)^{\ddagger}$ & $0.76^{* *}$ & $0.73^{* *}$ \\
\hline Vitamin K $(\mathrm{mg} / \text { day })^{\ddagger}$ & $0.82^{* *}$ & $0.68^{* *}$ \\
\hline Vitamins B1 (mg/day) $)^{\ddagger}$ & $0.80^{* *}$ & $0.78^{* *}$ \\
\hline Vitamins B2 $(\mathrm{mg} / \text { day })^{\ddagger}$ & $0.82^{* *}$ & $0.77^{* *}$ \\
\hline $\operatorname{Niacin}(\mathrm{mg} / \text { day })^{\ddagger}$ & $0.80^{* *}$ & $0.77^{* *}$ \\
\hline Vitamin B6 $(\mathrm{mg} / \text { day })^{\ddagger}$ & $0.82^{* *}$ & $0.77^{* *}$ \\
\hline Vitamin B12 $(\mu \mathrm{g} / \text { day })^{\ddagger}$ & $0.76^{* *}$ & $0.71^{* *}$ \\
\hline Folic acid $(\mu \mathrm{g} / \text { day })^{\ddagger}$ & $0.81^{* *}$ & $0.67^{* *}$ \\
\hline Pantothenic acid $(\mathrm{mg} / \text { day })^{\ddagger}$ & $0.84^{* *}$ & $0.79^{* *}$ \\
\hline Vitamins C (mg/day $)^{\ddagger}$ & $0.72^{* *}$ & $0.61^{* *}$ \\
\hline Cholesterol $(\mathrm{mg} / \text { day })^{\ddagger}$ & $0.80^{* *}$ & $0.67^{* *}$ \\
\hline Dietary fiber $(g / \text { day })^{\ddagger}$ & $0.78^{* *}$ & $0.77^{* *}$ \\
\hline Saturated fatty acid $(\mathrm{g} / \text { day })^{\ddagger}$ & $0.81^{* *}$ & $0.80^{* *}$ \\
\hline Monounsaturated fatty acid $(\mathrm{g} / \text { day })^{\ddagger}$ & $0.78^{* *}$ & $0.74^{* *}$ \\
\hline Polyunsaturated fatty acid (g/day) ${ }^{\ddagger}$ & $0.78^{* *}$ & $0.72^{* *}$ \\
\hline $\mathrm{n}-3$ polyunsaturated fatty acid $(\mathrm{mg} / \text { day })^{\ddagger}$ & $0.56^{* *}$ & $0.72^{* *}$ \\
\hline $\mathrm{n}-6$ polyunsaturated fatty acid $(\mathrm{mg} / \text { day })^{\ddagger}$ & $0.55^{* *}$ & $0.71^{* *}$ \\
\hline Myristic acid (mg/day) $)^{\ddagger}$ & $0.71^{* *}$ & $0.82^{* *}$ \\
\hline Oleic acid $(\mathrm{mg} / \text { day })^{\ddagger}$ & $0.57^{* *}$ & $0.74^{* *}$ \\
\hline Linoleic acid $(\mathrm{mg} / \text { day })^{\ddagger}$ & $0.54^{* *}$ & $0.71^{* *}$ \\
\hline Alpha-linolenic acid (mg/day) $)^{\ddagger}$ & $0.58^{* *}$ & $0.70^{* *}$ \\
\hline Arachidonic acid (mg/day) $)^{\ddagger}$ & $0.61^{* *}$ & $0.68^{* *}$ \\
\hline Icosapentaenoic acid (mg/day) $)^{\ddagger}$ & $0.56^{* *}$ & $0.63^{* *}$ \\
\hline Docosahexaenoic acid $(\mathrm{mg} / \text { day })^{\ddagger}$ & $0.55^{* *}$ & $0.65^{* *}$ \\
\hline
\end{tabular}

\#: The data (Alpha tocopherol, Vitamin K, Vitamins B1, B2, Niacin, B6, and B12) were transformed by natural log to improve normality.

CFFQ: Food frequency questionnaire for dietary assessment in children. AFFQ: Food frequency questionnaire for dietary assessment in adults. **: $p<0.01$.

AD group $(2257 \pm 643 \mathrm{kcal} /$ day $)$. The median percent difference between the WDRs and AFFQ with regard to nutrients was $17 \%$ in the YC group and $11 \%$ in the AD group. Table 4 shows the correlation coefficients of energy, nutrients and fatty acids between the WDRs and 







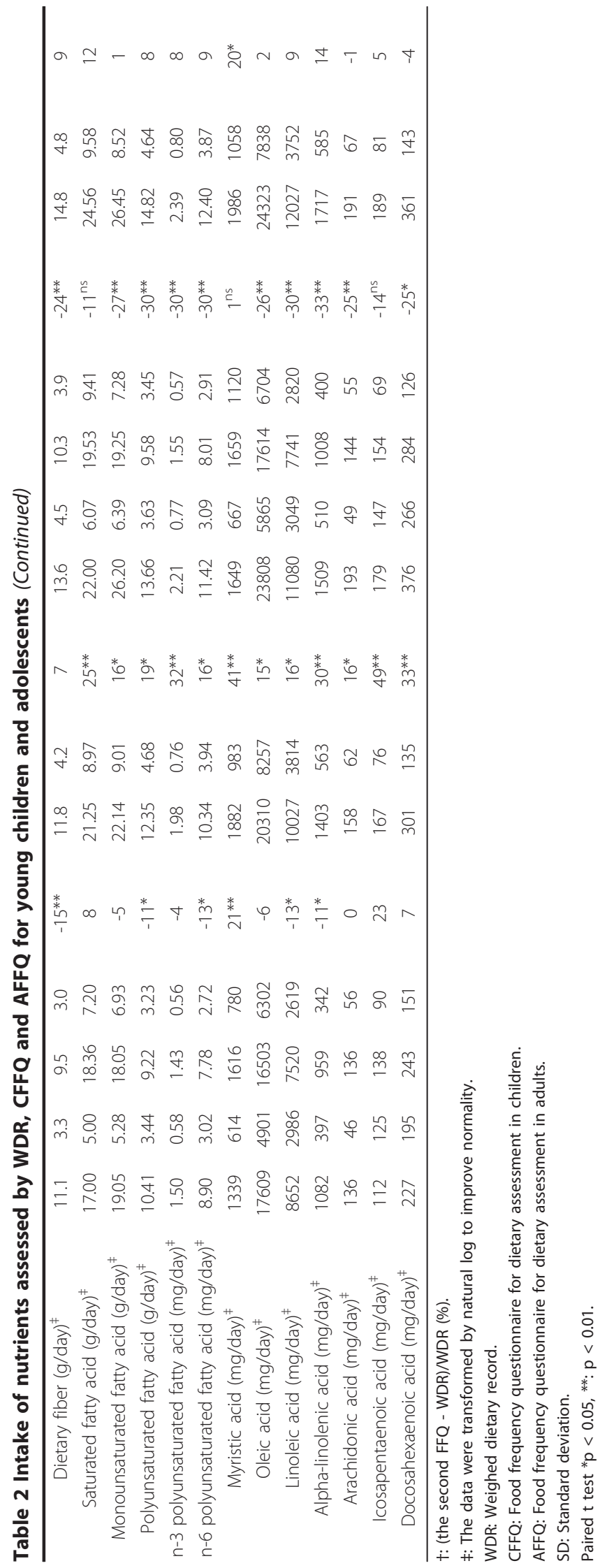


Table 3 Correlation coefficients of nutrients between the WDRs and the CFFQ for young children and adolescents

\begin{tabular}{|c|c|c|c|c|}
\hline \multirow[t]{2}{*}{ Nutrients } & \multicolumn{2}{|c|}{ Young children $(n=48)$} & \multicolumn{2}{|c|}{ Adolescents $(n=41)$} \\
\hline & crude value $^{a}$ & adjusted value $^{b}$ & crude value $^{a}$ & adjusted value $^{b}$ \\
\hline Energy (kcal/day) & $0.66^{* *}$ & & $0.33^{*}$ & \\
\hline Protein (g/day) & $0.66^{* *}$ & 0.19 & $0.37^{*}$ & 0.23 \\
\hline Total fat (g/day) & $0.51^{* *}$ & $0.50^{* *}$ & 0.14 & 0.19 \\
\hline Carbohydrate (g/day) & $0.66^{* *}$ & $0.38^{* *}$ & $0.39^{*}$ & 0.22 \\
\hline Sodium (mg/day) & $0.40^{* *}$ & 0.17 & 0.23 & 0.26 \\
\hline Potassium (mg/day) & $0.63^{* *}$ & $0.45^{* *}$ & 0.24 & $0.44^{* *}$ \\
\hline Calcium (mg/day) & $0.58^{* *}$ & $0.34^{*}$ & 0.28 & 0.26 \\
\hline Magnesium (mg/day) & $0.60^{* *}$ & $0.69^{* *}$ & 0.13 & 0.19 \\
\hline Phosphorous (mg/day) & $0.65^{* *}$ & $0.29^{*}$ & 0.30 & 0.15 \\
\hline Iron (mg/day) & $0.47^{* *}$ & 0.16 & 0.20 & $0.47^{* *}$ \\
\hline Zinc (mg/day) & $0.59^{* *}$ & 0.21 & $0.33^{*}$ & 0.16 \\
\hline Copper (mg/day) & $0.59^{* *}$ & 0.25 & 0.24 & $0.42^{* *}$ \\
\hline Manganese (mg/day) & $0.73^{* *}$ & $0.59^{* *}$ & $0.31^{*}$ & $0.36^{*}$ \\
\hline Vitamin A ( $\mu g R E /$ day) & $0.59^{* *}$ & 0.27 & $0.31^{*}$ & $0.34^{*}$ \\
\hline Vitamin D ( $\mu \mathrm{g} /$ day) & $0.43^{* *}$ & $0.33^{*}$ & 0.15 & 0.20 \\
\hline Alpha tocopherol (mg/day $)^{\ddagger}$ & $0.55^{* *}$ & $0.40^{* *}$ & 0.13 & $0.43^{* *}$ \\
\hline Vitamin $\mathrm{K}(\mu \mathrm{g} / \text { day })^{\ddagger}$ & $0.43^{* *}$ & $0.41^{* *}$ & 0.23 & $0.58^{* *}$ \\
\hline Vitamins B1 (mg/day $)^{\ddagger}$ & $0.57^{* *}$ & $0.31^{*}$ & 0.11 & $0.38^{*}$ \\
\hline Vitamins B2 (mg/day) $)^{\ddagger}$ & $0.70^{* *}$ & $0.48^{* *}$ & $0.38^{*}$ & $0.40^{*}$ \\
\hline Niacin $(m g / \text { day })^{\ddagger}$ & $0.61^{* *}$ & 0.14 & $0.42^{* *}$ & $0.46^{* *}$ \\
\hline Vitamin B6 $(\mathrm{mg} / \text { day })^{\ddagger}$ & $0.70^{* *}$ & $0.42^{* *}$ & $0.40^{*}$ & $0.56^{* *}$ \\
\hline Vitamin B12 $(\mu \mathrm{g} / \text { day })^{\ddagger}$ & $0.43^{* *}$ & 0.16 & $0.40^{*}$ & 0.31 \\
\hline Folic acid $(\mu \mathrm{g} / \text { day })^{\neq}$ & $0.55^{* *}$ & $0.47^{* *}$ & 0.28 & $0.64^{* *}$ \\
\hline Pantothenic acid $(\mathrm{mg} / \text { day })^{\ddagger}$ & $0.69^{* *}$ & $0.43^{* *}$ & $0.38^{*}$ & $0.37^{*}$ \\
\hline Vitamins $C(\mathrm{mg} / \text { day })^{\ddagger}$ & $0.33^{*}$ & 0.03 & $0.31^{*}$ & $0.77^{* *}$ \\
\hline Cholesterol $(\mathrm{mg} / \text { day })^{\ddagger}$ & $0.47^{* *}$ & $0.32^{*}$ & $0.34^{*}$ & 0.30 \\
\hline Dietary fiber $(g / \text { day })^{\ddagger}$ & $0.56^{* *}$ & $0.51^{* *}$ & 0.22 & $0.47^{* *}$ \\
\hline Saturated fatty acid (g/day) $)^{\ddagger}$ & $0.60^{* *}$ & $0.44^{* *}$ & 0.16 & $0.47^{* *}$ \\
\hline Monounsaturated fatty acid $(\mathrm{g} / \text { day })^{\ddagger}$ & $0.50^{* *}$ & $0.41^{* *}$ & 0.11 & 0.15 \\
\hline Polyunsaturated fatty acid (g/day) ${ }^{\ddagger}$ & $0.46^{* *}$ & $0.57^{* *}$ & 0.07 & 0.26 \\
\hline $\mathrm{n}-3$ polyunsaturated fatty acid $(\mathrm{mg} / \text { day })^{\ddagger}$ & $0.54^{* *}$ & $0.56^{* *}$ & 0.16 & $0.36^{*}$ \\
\hline $\mathrm{n}-6$ polyunsaturated fatty acid $(\mathrm{mg} / \text { day })^{\ddagger}$ & $0.43^{* *}$ & $0.56^{* *}$ & 0.05 & 0.23 \\
\hline Myristic acid (mg/day $)^{\ddagger}$ & $0.68^{* *}$ & 0.27 & $0.34^{*}$ & $0.44^{* *}$ \\
\hline Oleic acid $(\mathrm{mg} / \text { day })^{\ddagger}$ & $0.48^{* *}$ & $0.43^{* *}$ & 0.06 & 0.15 \\
\hline Linoleic acid $(\mathrm{mg} / \text { day })^{\ddagger}$ & $0.43^{* *}$ & $0.56^{* *}$ & 0.04 & 0.23 \\
\hline Alpha-linolenic acid (mg/day) $)^{\ddagger}$ & $0.37^{*}$ & $0.47^{* *}$ & -0.06 & 0.17 \\
\hline Arachidonic acid $(\mathrm{mg} / \text { day })^{\ddagger}$ & $0.50^{* *}$ & $0.34^{*}$ & $0.42^{* *}$ & $0.39^{*}$ \\
\hline Icosapentaenoic acid $(\mathrm{mg} / \text { day })^{\ddagger}$ & $0.48^{* *}$ & $0.35^{*}$ & 0.30 & $0.34^{*}$ \\
\hline Docosahexaenoic acid (mg/day) ${ }^{\ddagger}$ & $0.52^{* *}$ & $0.37^{*}$ & 0.30 & 0.31 \\
\hline
\end{tabular}

a: Unadjusted Pearson correlation coefficient.

b: Nutrient intakes were adjusted for age, sex and energy.

‡: The data (Alpha tocopherol, Vitamin K, Vitamin B1, Vitamin B2, Niacin, Vitamin B6, and Vitamin B12) were transformed by natural log to improve normality. CFFQ: Food frequency questionnaire for dietary assessment in children.

AFFQ: Food frequency questionnaire for dietary assessment in adults.

WDR: Weighed dietary record.

SD: Standard deviation.

${ }^{*} p<0.05,{ }^{* *}: p<0.01$. 
Table 4 Correlation coefficients of nutrients between the WDRs and the AFFQ for young children and adolescents

\begin{tabular}{|c|c|c|c|c|}
\hline \multirow[t]{2}{*}{ Nutrients } & \multicolumn{2}{|c|}{ Young children $(n=48)$} & \multicolumn{2}{|c|}{ Adolescents $(n=41)$} \\
\hline & crude value $^{a}$ & adjusted value $^{b}$ & crude value $^{a}$ & adjusted value $^{b}$ \\
\hline Energy (kcal/day) & $0.57^{* *}$ & & 0.31 & \\
\hline Protein (g/day) & $0.55^{* *}$ & 0.15 & 0.25 & $0.32^{*}$ \\
\hline Total fat (g/day) & $0.41^{* *}$ & 0.23 & -0.07 & -0.01 \\
\hline Carbohydrate (g/day) & $0.57^{* *}$ & 0.17 & $0.45^{* *}$ & -0.01 \\
\hline Sodium (mg/day) & $0.39^{* *}$ & $0.41^{* *}$ & 0.30 & $0.41^{* *}$ \\
\hline Potassium (mg/day) & $0.54^{* *}$ & $0.53^{* *}$ & 0.25 & $0.34^{*}$ \\
\hline Calcium (mg/day) & $0.50^{* *}$ & $0.33^{*}$ & $0.37^{*}$ & $0.50^{* *}$ \\
\hline Magnesium (mg/day) & $0.50^{* *}$ & $0.68^{* *}$ & 0.16 & 0.17 \\
\hline Phosphorous (mg/day) & $0.54^{* *}$ & 0.28 & 0.28 & 0.25 \\
\hline Iron (mg/day) & $0.41^{* *}$ & 0.27 & 0.25 & $0.44^{* *}$ \\
\hline Zinc (mg/day) & $0.49^{* *}$ & 0.22 & $0.36^{*}$ & 0.05 \\
\hline Copper (mg/day) & $0.51^{* *}$ & $0.47^{* *}$ & $0.40^{*}$ & $0.45^{* *}$ \\
\hline Manganese (mg/day) & $0.71^{* *}$ & $0.61^{* *}$ & 0.26 & 0.15 \\
\hline Vitamin A ( $\mu g R E /$ day) & 0.25 & $0.42^{* *}$ & 0.21 & 0.30 \\
\hline Vitamin D ( $\mu \mathrm{g} /$ day) & 0.23 & 0.24 & 0.17 & 0.26 \\
\hline Alpha tocopherol $(\mathrm{mg} / \text { day })^{\ddagger}$ & 0.11 & 0.21 & 0.01 & 0.28 \\
\hline Vitamin $\mathrm{K}(\mu \mathrm{g} / \text { day })^{\ddagger}$ & 0.16 & $0.35^{*}$ & 0.28 & $0.43^{* *}$ \\
\hline Vitamins B1 (mg/day $)^{\ddagger}$ & $0.48^{* *}$ & $0.37^{*}$ & 0.02 & 0.22 \\
\hline Vitamins B2 (mg/day) $)^{\ddagger}$ & 0.24 & 0.29 & $0.33^{*}$ & $0.37^{*}$ \\
\hline Niacin $(m g / \text { day })^{\ddagger}$ & 0.22 & $0.34^{*}$ & $0.34^{*}$ & $0.38^{*}$ \\
\hline Vitamin B6 $(\mathrm{mg} / \text { day })^{\ddagger}$ & $0.33^{*}$ & $0.50^{* *}$ & 0.24 & $0.38^{*}$ \\
\hline Vitamin B12 $(\mu \mathrm{g} / \text { day })^{\ddagger}$ & 0.21 & $0.32^{*}$ & 0.31 & 0.25 \\
\hline Folic acid $(\mu \mathrm{g} / \text { day })^{\neq}$ & 0.18 & $0.46^{* *}$ & 0.16 & $0.43^{* *}$ \\
\hline Pantothenic acid $(\mathrm{mg} / \text { day })^{\ddagger}$ & 0.26 & $0.33^{*}$ & 0.29 & 0.23 \\
\hline Vitamins C (mg/day $)^{\ddagger}$ & 0.25 & 0.28 & 0.24 & $0.51^{* *}$ \\
\hline Cholesterol $(\mathrm{mg} / \text { day })^{\ddagger}$ & 0.09 & $0.29^{*}$ & 0.20 & 0.09 \\
\hline Dietary fiber $(g / \text { day })^{\ddagger}$ & $0.51^{* *}$ & $0.61^{* *}$ & 0.21 & $0.42^{* *}$ \\
\hline Saturated fatty acid (g/day) $)^{\ddagger}$ & $0.54^{* *}$ & $0.31^{*}$ & 0.02 & $0.32^{*}$ \\
\hline Monounsaturated fatty acid $(\mathrm{g} / \text { day })^{\ddagger}$ & $0.35^{*}$ & 0.19 & -0.13 & 0.02 \\
\hline Polyunsaturated fatty acid (g/day) ${ }^{\ddagger}$ & 0.13 & 0.16 & -0.09 & 0.23 \\
\hline $\mathrm{n}-3$ polyunsaturated fatty acid $(\mathrm{mg} / \text { day })^{\ddagger}$ & $0.33^{*}$ & $0.33^{*}$ & 0.09 & $0.35^{*}$ \\
\hline $\mathrm{n}-6$ polyunsaturated fatty acid $(\mathrm{mg} / \text { day })^{\ddagger}$ & 0.18 & 0.15 & -0.09 & 0.19 \\
\hline Myristic acid (mg/day $)^{\ddagger}$ & $0.64^{* *}$ & 0.18 & $0.35^{*}$ & $0.63^{* *}$ \\
\hline Oleic acid (mg/day) $)^{\ddagger}$ & $0.37^{*}$ & 0.19 & -0.13 & 0.01 \\
\hline Linoleic acid $(\mathrm{mg} / \text { day })^{\ddagger}$ & 0.17 & 0.16 & -0.09 & 0.20 \\
\hline Alpha-linolenic acid (mg/day) $)^{\ddagger}$ & 0.11 & 0.01 & -0.06 & 0.24 \\
\hline Arachidonic acid $(\mathrm{mg} / \text { day })^{\ddagger}$ & $0.45^{* *}$ & 0.22 & 0.17 & 0.03 \\
\hline Icosapentaenoic acid $(\mathrm{mg} / \text { day })^{\ddagger}$ & $0.44^{* *}$ & $0.39^{* *}$ & 0.27 & $0.34^{*}$ \\
\hline Docosahexaenoic acid (mg/day) ${ }^{\ddagger}$ & $0.38^{* *}$ & $0.35^{*}$ & 0.29 & 0.31 \\
\hline
\end{tabular}

a: Unadjusted Pearson correlation coefficient.

b: Nutrient intakes were adjusted for age, sex and energy.

‡: The data (Alpha tocopherol, Vitamin K, Vitamin B1, Vitamin B2, Niacin, Vitamin B6, and Vitamin B12) were transformed by natural log to improve normality. CFFQ: Food frequency questionnaire for dietary assessment in children.

AFFQ: Food frequency questionnaire for dietary assessment in adults.

WDR: Weighed dietary record.

SD: Standard deviation.

${ }^{*} p<0.05,{ }^{* *}: p<0.01$. 
the second $\mathrm{AFFQ}$ in the $\mathrm{YC}$ and $\mathrm{AD}$ groups. In the $\mathrm{AFFQ}$, the adjusted values varied from 0.01 for Alpha-linolenic acid to 0.68 for magnesium in the $\mathrm{YC}$ group (the median; $\mathrm{r}=0.30$ ), and from -0.01 for carbohydrate to 0.63 for Myristic acid in the AD group (the median; $r=0.29$ ).

\section{Comparison of correlation coefficients for the different FFQs}

We classified the nutrients and fatty acids by their correlation coefficient in adjusted values into 3 categories, 'less than 0.30 ' (low), ' 0.30 or more but less than 0.50 ' (medium) and '0.50 or more' (high) based on the CFFQ and AFFQ. For the CFFQ, the number of nutrients classified as low, medium, and high was 11,19 and 9 in the $\mathrm{YC}$ group, and 16, 18 and 5 in the $\mathrm{AD}$ group, respectively. And for the AFFQ, the number of nutrients was 19,15 and 5 in the YC group and 21, 15 and 3 in the AD group.

\section{Bland Altman analysis}

The agreements between the WDR and CFFQ or the WDR and AFFQ were assessed using Bland Altman analysis (Figures 2 and 3). The intake of energy and 18 nutrients (carbohydrate, potassium, zinc, copper, vitamin $\mathrm{D}$, alpha tocopherol, vitamin $\mathrm{K}$, vitamin $\mathrm{B} 1$, vitamin $\mathrm{B} 2$, vitamin B6, folic acid, monounsaturated fatty acid, $n-3$ polyunsaturated fatty acid, oleic acid, linoleic acid, alpha-linolenic acid, and arachidonic acid) in the CFFQ and the intake of energy and 11 nutrients (protein, carbohydrate, zinc, copper, vitamin D, alpha tocopherol, vitamin $\mathrm{K}$, vitamins $\mathrm{B} 1$, folic acid, vitamin $\mathrm{C}$ ) in the AFFQ showed agreement between the two methods.

\section{Discussion}

Correlation coefficients on the order of 0.5 to 0.7 appear to be typical for the reproducibility of nutrient intake [15]. Cullen et al. $(r=0.21-0.72)$ [16] and Teiber et al. $(r=0.42-0.74)$ [17] reported reproducibility of FFQs for children. In our study, the correlation coefficients between the first and second FFQs were higher $(r=$ 0.76 in $C F F Q, r=0.73$ in $A F F Q)$ than those in their reports.

We had assumed that the CFFQ would be a more suitable method for assessing children's diets than the AFFQ. The median of the adjusted values between the WDRs and CFFQ were $\mathrm{r}=0.39$ in the $\mathrm{YC}$ group and $\mathrm{r}=0.34$ in the AD group. The value between the WDRs and AFFQ were $r=0.30$ and $r=0.29$, respectively. The same moderate correlations were reported by Rockett et al. ( $\mathrm{r}=0.21-0.58)$ [2], Marshall et al. $(\mathrm{r}=0.20-0.52)$ [18], and Blum et al. $(r=0.26-0.63)$ [19]. When we classified the energy and nutrients by their correlation coefficients in adjusted values into 3 categories, for the YC group, the number of nutrients classified as medium and high was 28 in the CFFQ and 20 in the AFFQ. For the AD group, the number was 23 and 18, respectively. Comparing the CFFQ and AFFQ, the CFFQ was more suitable than the AFFQ in both the YC and AD group.

In our study, we found a small difference between the $\mathrm{YC}$ and $\mathrm{AD}$ groups in terms of the CFFQ or AFFQ.Cullen et al. compared the validity of the FFQ between a group of 10 to 12 -year-old children and 13 to 17 -yearold adolescents [16]. They reported that the validity was higher in the 13 to 17 -year-old group, probably because knowledge about foods or dishes was greater among the

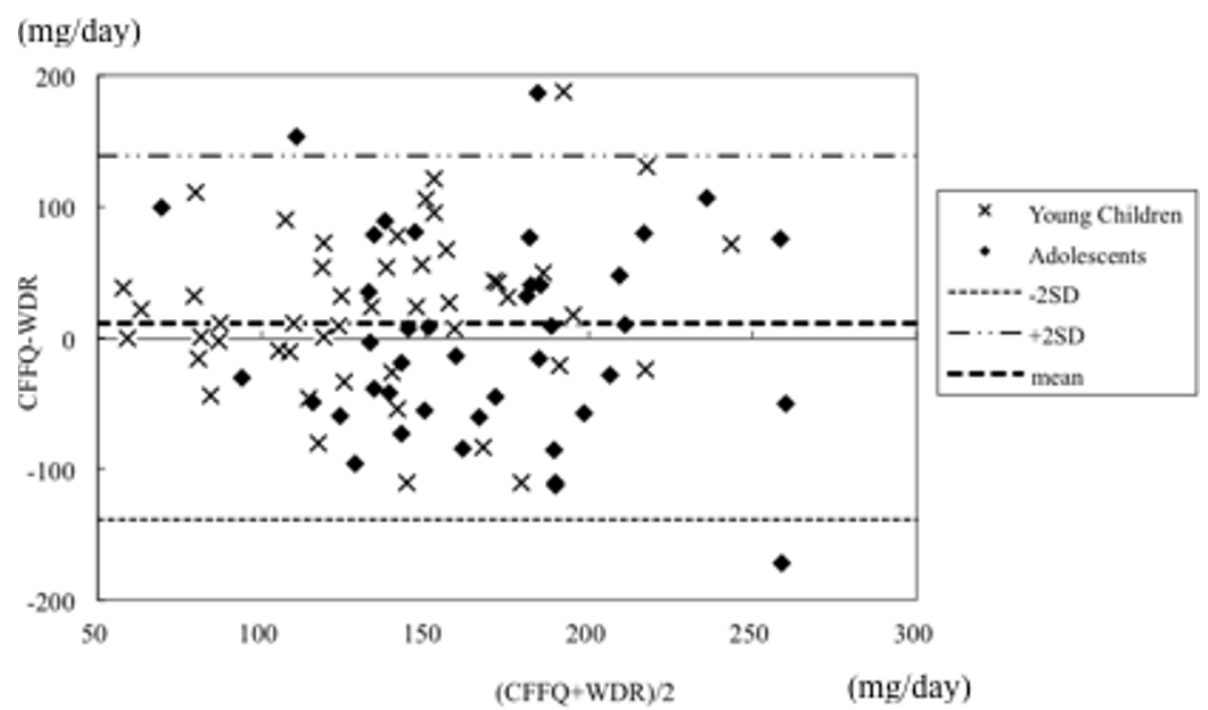

Figure 2 Agreement of the estimates of arachidonic acid intake between the four WDRs and the CFFQ for all subjects. CFFQ: Food frequency questionnaire for dietary assessment in children. WDR: Weighed dietary record. SD: Standard deviation. 


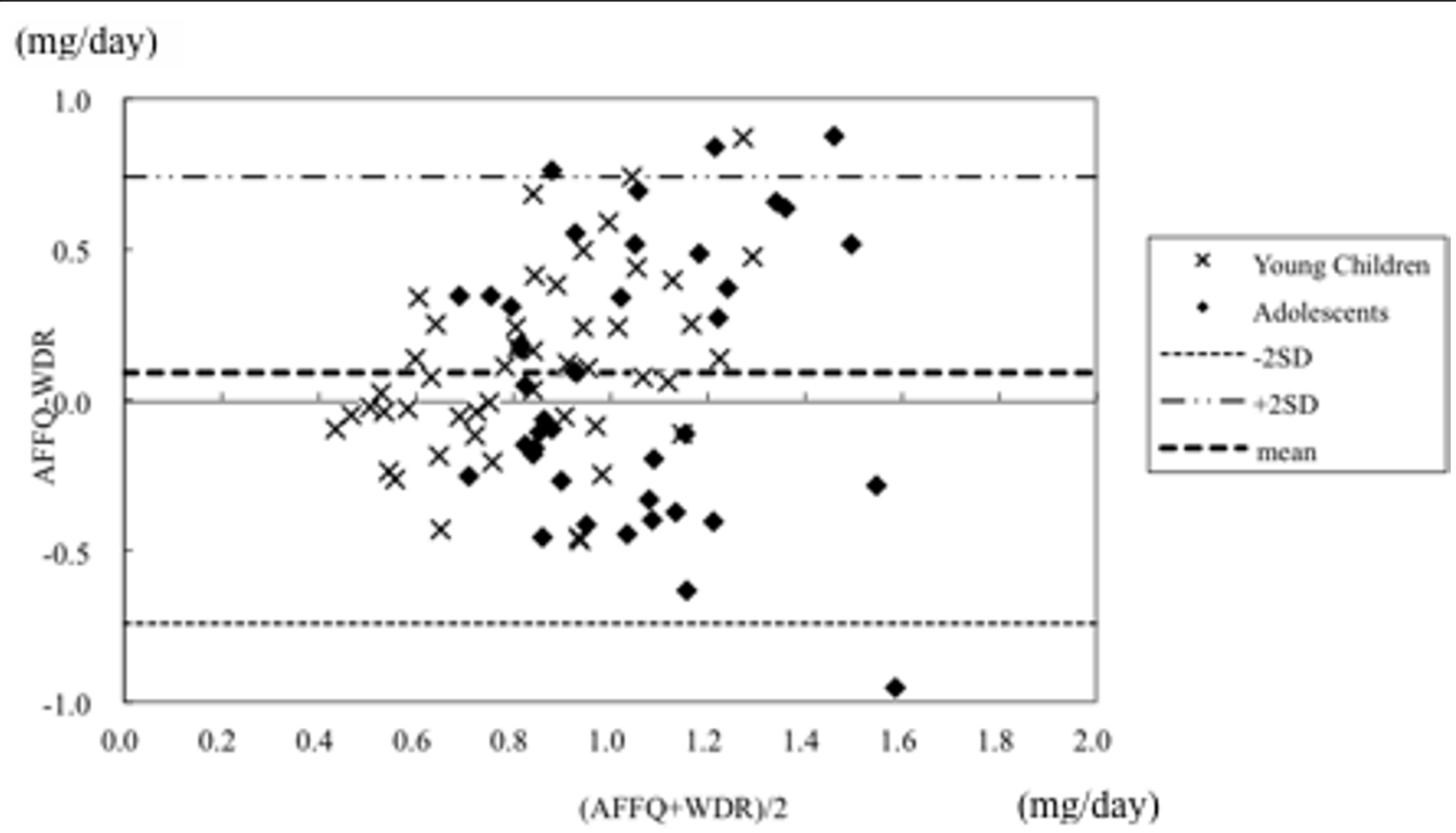

Figure 3 Agreement of the estimates of vitamin B1 intake between the four WDRs and the AFFQ for all subjects. AFFQ: Food frequency questionnaire for dietary assessment in adults. WDR: Weighed dietary record. SD: Standard deviation.

older subjects. However, we obtained higher median adjusted values between the WDRs and CFFQ or the WDRs and AFFQ in the YC group than in the AD group. The reason for such differences might have been because the mother completed both the WDRs and FFQs for the subjects in the YC group, while in the AD group, although FFQs were completed by the subjects, the WDRs were completed by either the subjects or their mothers. Because we considered that the subjects in the AD group had more opportunities to eat foods and snacks unknown to their guardians/parents than those in the YC group, we asked the subjects in the $\mathrm{AD}$ group to complete the FFQs. However, it might be possible that they had less knowledge about intake frequencies and the portion sizes of the dishes or foods than the mothers in the $\mathrm{YC}$ group. To maintain the quality of the data, the registered dieticians asked to the subjects to clarify any unclear answers.

We obtained different correlation coefficients for the same nutrients from the CFFQ and AFFQ, including sodium in the YC group $(r=0.17$ in the CFFQ and $r=$ 0.41 in the AFFQ). It is necessary to develop specific FFQs for the group being studied (to accurately reflect socioeconomic, cultural, and seasonal differences). The AFFQ was developed based on the dietary data of adults who lived in several different areas of Japan. Therefore, the AFFQ might have sufficiently covered the dishes and individual foods consumed by subjects in this study. However, the AFFQ was found to have lower correlation coefficients of total fat and fatty acids than the CFFQ, especially in the YC group. It may be necessary to modify a food list in the AFFQ to add foods influencing fat that are regularly eaten by children, and are familiar to children, such as snacks.

Generally, a FFQ originally developed for adults is applied for the assessment of dietary intake in children, however it has been reported that when the FFQ for adults is used, the dietary intake of children is overestimated [5-7]. Fumagalli et al. [5] studied the validity of a FFQ for 5 to 10 year old children, and Wilson [6] studied the validity of a FFQ for 4 to 9 year old children. These authors compared the improved FFQs for adults with 3-day WDRs. They reported that energy and nutrient intakes in the FFQs were overestimated. In our study, we compared the differences in nutrient intake between the WDRs and FFQs. The numbers of over/ underestimated nutrients were lower from the CFFQ in the YC group and from the AFFQ in the AD group. The portion size of a FFQ should be suitable for the subjects. Because steamed rice is a particularly important energy source in Japan, it is important to determine the intake of steamed rice as accurately as possible, and three sizes of rice bowls (large, medium, and small) were included in the questionnaire in both the CFFQ 
and AFFQ (150 g, $120 \mathrm{~g}$, and $80 \mathrm{~g}$ in the CFFQ and $200 \mathrm{~g}, 150 \mathrm{~g}$ and $100 \mathrm{~g}$ in the AFFQ). The portion size of the CFFQ is appropriate for 3 to 11 year old children, because the CFFQ was developed for this age-group children. Since the AFFQ was developed for adults, the portion size of the AFFQ might be more suitable for the subjects in the $\mathrm{AD}$ group who were bigger than those in the YC group.

The values of sodium intake in the CFFQ were underestimated compared to the WDR. In contrast, the values in the AFFQ were overestimated in both the $\mathrm{YC}$ and AD groups. The systematic errors were found. For example, when we collected dietary data from children for developing the CFFQ, the subjects' parents/guardians freely decided the day for the WRD [10]. Although we asked subject's parents/guardians to have the children eat habitual diets on the day they selected for the WRD, it was possible that a special day (e.g. a holiday or other celebration where special foods are eaten) may have been selected. Therefore, the food list of the CFFQ might have posed the systematic errors.

In order to assess habitual intake, dietary surveys need to be conducted for several days [20]. However, the WDR is considered a burden some for subjects. In addition, it has been reported that long-term dietary surveys are not always accurate [21]. Therefore, we decided that the mean intake recorded in four WDRs, which were conducted on different days of the week, represented children's habitual dietary intake for one month.

In this study, the two types of FFQs, (i.e. CFFQ and AFFQ) were answered at the same time. We eliminated the any bias which may be caused by administration of the CFFQ and AFFQ by assuring that the order in which each FFQ was answered was randomly determined.

We were not able to assemble a large number of subjects of each sex and age. Therefore, we were not able to calculate the correlation coefficients by sex and age. For the growing children, it is thought that the amount and quality of the dietary intake differs by sex and age. Thus, we have adjusted for sex and age, in addition to energy, for correlation coefficients between the WDR and second FFQ.

We were not able to select subject candidates by random sampling because we had asked the teachers at each school to select participants. The four-day WDRs and 4 FFQs were a heavy burden for the subjects and their parents/guardians. To conduct a dietary survey at the kindergarten, elementary school, and secondary school, the cooperation of the teacher of each school was necessary to ensure that the parents/guardians understood the study. Therefore, the subjects and their mothers who participated in this study might have had more interest in their diets than the general population. In addition, because we specified the days of the dietary survey for subjects and their mothers, it was possible that the subjects may have eaten special meals on those days. Therefore, when we explained the study method to them, we asked them to eat habitual diets on the days of the dietary survey.

The CFFQ does not encompass the seasonal variation in the 75 food items, because when we developed the CFFQ from WDRs collected during only one season, between May and July [10]. To address this potential short-coming, we decided to add seasonal fruits for this study. However, this study was conducted in the only one season. We need the further study to assess the seasonal intakes.

To our knowledge, this is the first study to examine the reproducibility and validity of an FFQ including questions about both individual food items and mixed dishes in 3 to 16 year old Japanese children. The CFFQ might be a useful tool for assessing the habitual dietary intake of 3 to 11 year old children for epidemiologic studies in Japan. In order to more accurately estimate the dietary intake of 12 to 16 year old children, it is necessary to develop a new FFQ or further modify the existing AFFQ or CFFQ.

\section{Conclusions}

This study indicated that the CFFQ might be a useful tool for assessing habitual dietary intake of young children (ages 3-11). Although the CFFQ agreed moderately with habitual intakes, it was found to underestimate dietary intake in the $\mathrm{AD}$ group. In addition, using the AFFQ had a low ability to rank habitual intake. Therefore, it is necessary to design a new FFQ or modify an existing FFQ to accurately assess the habitual diet of children aged 12-16.

\section{Acknowledgements}

We thank the teachers, parents/guardians, and children of the kindergarten, elementary school and secondary school attached to the Nara Women's University for their participation in this study.

\section{Author details}

'Department of Food and Nutritional Sciences, School of Natural Science and Ecological Awareness, Graduate School of Humanities and Sciences, Nara Women's University, Kitauoya-nishimachi, Nara, 630-8506, Japan.

${ }^{2}$ Department of Food Science and Nutrition, Faculty of Human Environmental Sciences, Mukogawa Women's University, 6-46 Ikebiraki-cho, Nishinomiya, Hyogo 663-8558, Japan. ${ }^{3}$ Sanpoku Primary School in Murakami City, 526 Horinouchi, Murakami, Niigata, 959-3905, Japan. ${ }^{4}$ Department of Food Sciences and Nutrition, Faculty of Human Life and Environment, Nara Women's University, Kitauoya-nishimachi, Nara, 630-8506, Japan.

${ }^{5}$ Department of Food Science and Nutrition, Faculty of Wellness, Shigakukan university, 55 Nadakayama, Yokone-cho, Daifu, Aichi, 474-8651, Japan. ${ }^{6}$ Laboratory of Statistics, School of Medicine, Osaka City University, 1-4-3 Asahi-machi, Abeno-ku, Osaka, 545-8585, Japan. ${ }^{7}$ School of Human Science and Environment, University of Hyogo, 1-1-12 Motomachi-cho, Shinzaike, Himezi, 670-0092, Japan.

\section{Authors' contributions}

TK conceptualized the design of the study and study protocol, as well as performed data collection, statistical analyses and writing of the manuscript. MK, SI, CT and NO contributed to data collection. MF performed statistical 
analyses. CD contributed to the concept and design of the study and study protocol, as well as performed data collection and assisted in writing and editing the manuscript. All the authors read and approved the final manuscript.

\section{Competing interests}

The authors declare that they have no competing interests.

Received: 6 January 2010 Accepted: 24 March 2011

Published: 24 March 2011

\section{References}

1. Mikkilä V, Räsänen L, Raitakari OT, Pietinen P, Viikari J: Consistent dietary patterns identified from childhood to adulthood: the cardiovascular risk in Young Finns Study. Br J Nutr 2005, 93:923-931.

2. Rockett HR, Colditz GA: Assessing diets of children and adolescents. Am J ClinNutr 1997, 65:1116S-1122S.

3. Biró G, Hulshof KF, Ovesen L, Amorim Cruz JA, EFCOSUM Group: Selection of methodology to assess food intake. Eur J ClinNutr 2002, 56:S25-S32.

4. Livingstone $M B$, Robson PJ: Measurement of dietary intake in children. ProcNutrSoc 2000, 59:279-293.

5. Fumagalli F, Pontes Monteiro J, Sartorelli DS, Vieira MN, de Lourdes Pires Bianchi M: Validation of a food frequency questionnaire for assessing dietary nutrients in Brazilian children 5 to 10 years of age. Nutrition 2008, 24:427-432.

6. Wilson $\mathrm{AM}$, Lewis RD: Disagreement of energy and macronutrient intakes estimated from a food frequency questionnaire and 3-day diet record in girls 4 to 9 years of age. J Am Diet Assoc 2004, 104:373-378.

7. Serdula MK, Alexander MP, Scanlon KS, Bowman BA: What are preschool children eating? A review of dietary assessment. Annu Rev Nutr 2001, 21:475-498.

8. Bertoli S, Petroni ML, Pagliato E, Mora S, Weber G, Chiumello G, Testolin G: Validation of food frequency questionnaire for assessing dietary macronutrients and calcium intake in Italian children and adolescents. J PediatrGastroentero/Nutr 2005, 40:555-560.

9. Wakai $\mathrm{K}$ : A review of food frequency questionnaires developed and validated in Japan. J Epidemiol 2009, 19:1-11.

10. Kobayashi T, Tanaka S, Toji C, Kamimura M, Okamoto N, Imai S, Fukui M, Date C: Development of a food frequency questionnaire to estimate habitual dietary intake in Japanese children. Nutr J 2010, 9:17.

11. Date C, Yamaguchi M, Tanaka H: Development of a food frequency questionnaire in Japan. J Epidemiol 1997, 6:131S-136S.

12. Ministry of Education, Culture, Sports, Science and Technology: Standard tables of food composition in Japan fifth revised and enlarged edition. Tokyo: National Printing Bureau; 2005, (in Japanese).

13. Willett W, Stanpfer M: Implications of total energy intake for epidemiologic analyses. In Nutritional epidemiology.. 2 edition. Edited by: Willett W. Oxford: Oxford University Press; 1998:273-301.

14. Bland JM, Altman DG: Statistical methods for assessing agreement between two methods of clinical measurement. Lancet 1986, 1:307-310.

15. Willett W, Lenart E: Reproducibility and validity of Food-frequency questionnaires. In Nutritional epidemiology.. 2 edition. Edited by: Willett W. Oxford: Oxford University Press; 1998:101-147.

16. Cullen KW, Watson K, Zakeri I: Relative reliability and validity of the Block kids questionnaire among youth aged 10 to 17 years. J Am Diet Assoc 2008, 108:862-866.

17. Treiber FA, Leonard SB, Frank G, Musante L, Davis H, Strong WB, Levy M: Dietary assessment instruments for preschool children: reliability of parental responses to the 24-hour recall and a food frequency questionnaire. J Am Diet Assoc 1990, 90:814-820.

18. Marshall TA, Eichenberger Gilmore JM, Broffitt B, Stumbo PJ, Levy SM: Relative validity of the lowa Fluoride Study targeted nutrient semiquantitative questionnaire and the Block kids' food questionnaire for estimating beverage, calcium, and vitamin $D$ intakes by children. J Am Diet Assoc 2008, 108:465-472.

19. Blum RE, Wei EK, Rockett HR, Langeliers JD, Leppert J, Gardner JD, Colditz GA: Validation of a food frequency questionnaire in Native American and Caucasian children 1 to 5 years of age. Matern Child Health J 1999, 3:167-172.

20. Egami I, Wakai K, Kaitoh K, Kawamura T, Tamakoshi A, Lin Y, Nakayama T, Sugimoto K, Ohno Y: Intra- and inter-individual variations in diets of the middle-aged and the elderly. Nippon KoshuEiseiZasshi 1999, 46:828-837, (in Japanese).

21. Willett WC, Sampson L, Stampfer MJ, Rosner B, Bain C, Witschi J,

Hennekens CH, Speizer FE: Reproducibility and validity of a

semiquantitative food frequency questionnaire. Am J Epidemiol 1985, 122:51-65.

doi:10.1186/1475-2891-10-27

Cite this article as: Kobayashi et al:: Reproducibility and validity of the food frequency questionnaire for estimating habitual dietary intake in children and adolescents. Nutrition Journal 2011 10:27.

\section{Submit your next manuscript to BioMed Central and take full advantage of:}

- Convenient online submission

- Thorough peer review

- No space constraints or color figure charges

- Immediate publication on acceptance

- Inclusion in PubMed, CAS, Scopus and Google Scholar

- Research which is freely available for redistribution

Submit your manuscript at www.biomedcentral.com/submit
Ciomed Central 